\title{
PERIPARTUM HYSTERECTOMIES - LEADING RISK FACTORS AND CAUSES
}

\author{
Tihomir Totev, Desislava Staneva, Tsvetan Oslekov, Georgi Stamenov \\ Department of Obstetrics and Gynaecology, "Nadezhda” Women's Health Hos- \\ pital, Sofia, Bulgaria.
}

\begin{abstract}
Purpose: To define the frequency, significant factors and causes that necessitated peripartum hysterectomies.

Material and Methods: We studied retrospectively and prospectively 21 patients who underwent peripartum hysterectomies at "Nadezhda" Women's Health Hospital between January 2013 and July 2019.

Results: The frequency of peripartum hysterectomy was 1.96/1000 deliveries, and $95 \%$ of them were performed during or after a cesarean birth. The intrapartum ones were carried out mainly because of uterine atony or abnormal insertion of the placenta. The interventions made in the early postoperative period were undertaken in cases of severe pelvic inflammations and postoperative hematomas.

Conclusion: Patients undergoing cesarean section are at risk for peripartum haemorrhages, which are associated with many risk factors: previous cesarean section and other interventions such as myomectomy, placenta praevia.
\end{abstract}

Keywords: peripartum hysterectomy, postpartum haemorrhage

\section{INTRODUCTION}

Peripartum hysterectomy is a risky, life-preserving intervention, which is undertaken during or immediately after abdominal (cesarean hysterectomy) or vaginal birth, most often to manage a severe haemorrhage [1]. Another definition includes hysterectomies during birth and those performed before discharge. In the US, the frequency of emergency peripartum hysterectomy ranges between 0.8-2.28/1000 births [2, 3]. During the last decades, along with the increasing numbers of cesarean births, there has been an increase of cesarean hysterectomies, the latter being associated with higher morbidity and mortality rates $[3,4,5]$. The major risk factors include placenta praevia, placenta accreta, increta, percreta, and previous uterine surgery that increase the risks for rupture.

Postpartum haemorrhage is the leading cause of emergency peripartum hysterectomy. It is defined as a blood loss of more than $500 \mathrm{ml}$ during the first 24 hours after delivery. According to WHO data, postpartum haemorrhages account for $27 \%$ of maternal deaths in the 115 countries studied [6]. Expert estimations demonstrate that over $80 \%$ of maternal deaths because of postpartum haemorrhage could have been prevented using appropriate conservative and surgical treatment [7]. Conservative surgical treatment (vascular ligation) is necessary in $1.3 \%$ of the cases of postpartum haemorrhages, and emergency hysterectomies are imperative in $1.1 \%$ of such cases [7].

\section{PURPOSE}

This study aimed to determine the frequency, leading contributing factors and causes that warranted peripartum hysterectomy.

\section{MATERIAL AND METHODS}

We carried out this retrospective and prospective study at the Nadezhda Women's Health Hospital in Sofia, covering the period between January 2013 and end of June 2019. We analysed the data obtained from the case histories of a total of 10724 deliveries. We focused on the intrapartum hysterectomies, as well as on those performed after birth and before discharge. We applied descriptive analysis to process the data.

\section{RESULTS}

The total number of the peripartum hysterectomies was 21 , accounting for $1.96 / 1000$ deliveries. Of these, 14 hysterectomies $(66.6 \%)$ were total, and $7(33.3 \%)$ were supracervical. The age range of the patients was 28-47, mean age 37 years. 


\section{The investigated factors included:}

\section{Delivery mechanism}

Twenty hysterectomies were performed after cesarean section and only one - after vaginal birth. In three cases, there was a history of cesarean section.

\section{tuses}

II. Types of conception and number of fe-

Thirteen patients $(61.9 \%)$ with peripartum hysterectomy $13(61.9 \%)$ had conceived after IVF/ ET, and eight patients $(38.1 \%)$ had conceived naturally. Fifteen of the pregnancies were singleton, five were twin, and there was one triplet pregnancy.

Fig. 1. Causes for peripartum hysterectomy

\section{Number of births}

Thirteen patients $(61.9 \%)$ gave birth for the first time; it was the second for $6(28.6 \%)$, and third in 2 women $(9.5 \%)$.

IV. Previous uterine surgeries

One-third of the investigated patients had had uterine surgery: 3 had had a cesarean section, two had undergone myomectomy, and three had had other interventions, including one with radical trachelectomy.

\section{Concomitant uterine diseases}

Four patients had concomitant uterine pathology, two of these had myomas.

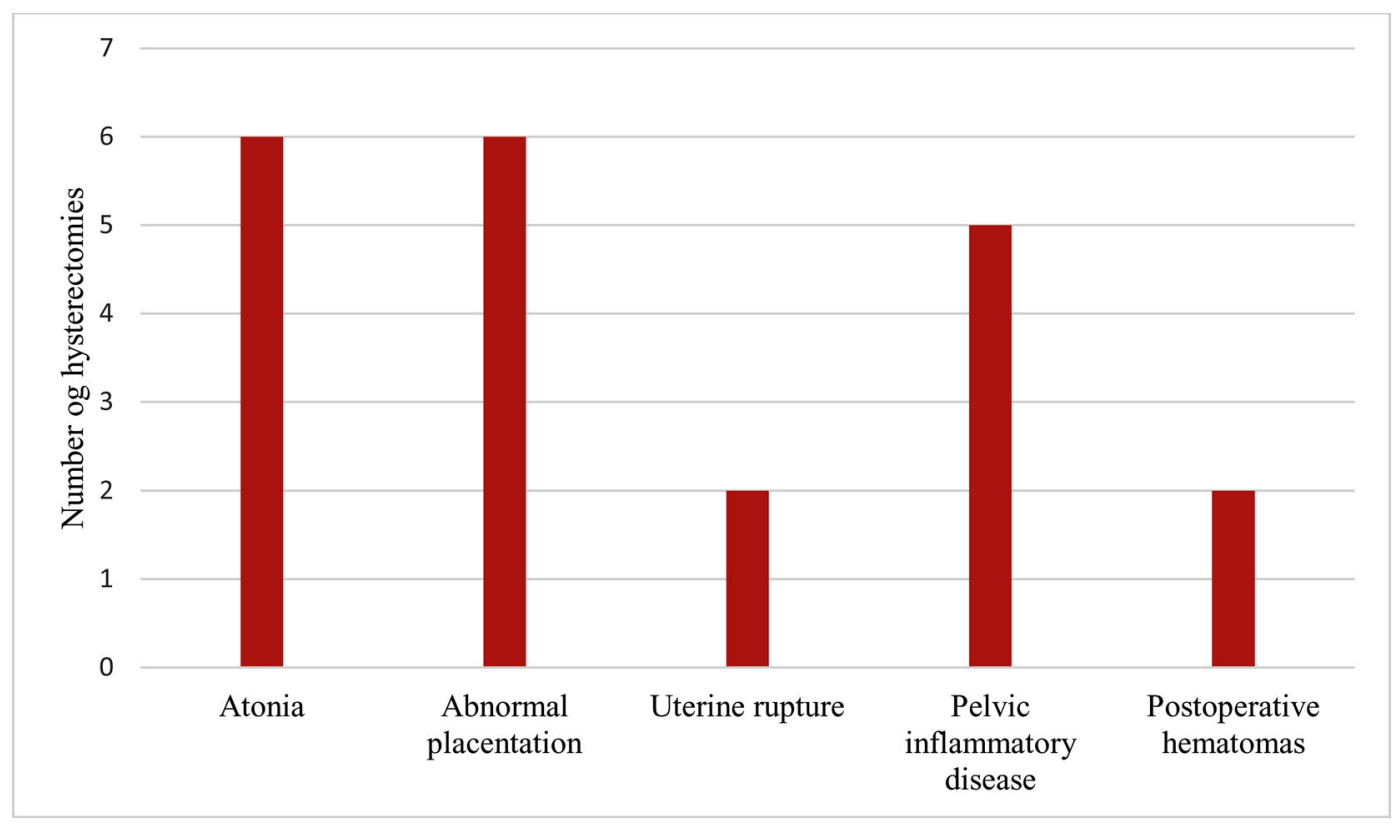

\section{DISCUSSION}

The frequency of the peripartum hysterectomies (1.96/1000 births) at our hospital is close to the data reported in the literature [2,3]. We suppose that placing a Bakri balloon in the uterus for postpartum haemorrhages after vaginal birth or after a cesarean section has in many cases prevented hysterectomy as an extreme life-saving measure. Our observations are supported by other studies $[8$, 9]. The frequency of severe postoperative complications was $9.5 \%$ : in one patient with three relaparotomies for hemoperitoneum and another with re-laparotomies because of an intestinal lesion.

Our study has shown that cesarean birth was a major risk factor since $95 \%$ of the peripartum hysterectomies were performed during and after cesarean section.
Nearly one-third of the patients who underwent peripartum hysterectomy had conceived after IVF/ET. Most of them had a history of uterine interventions and had received hormonal and tocolytic treatment during pregnancy. All of these factors are associated with abnormal placentation and diminished uterine contractility.

The analysis of causes for peripartum hysterectomy showed that intrapartum hysterectomies were most often imposed by uterine atony and abnormal insertion of the placenta. The hysterectomies in the early postoperative period were undertaken because of severe pelvic infections (endomyometritis, purulent pelvic peritonitis) and postoperative hematomas. 


\section{CONCLUSION}

Patients giving birth by cesarean section represent a risk group for peripartum haemorrhages. There are other risk factors to be considered: a previous cesarean birth and other uterine surgical operations (myomectomy), placenta praevia, all of which are actually indications for the surgical intervention. Reducing the number of cesarean deliveries, and especially those on maternal request would decrease the frequency of risk factors for peripartum haemorrhages, thus reducing the inevitability for this dramatic life-saving intervention.

\section{REFERENCES:}

1. Christopoulos P, Hassiakos D, Tsitoura A, Panoulis K, Papadias K, Vitoratos N. Obstetric hysterectomy. A review of cases over 16 years. J Obstet Gynaecol. 2011; 31(2):139-41. [PubMed] [Crossref]

2. Forna F, Miles AM, Jamieson DJ. Emergency peripartum hysterectomy: a comparison of cesarean and postpartum hysterectomy. Am J Obstet Gynecol. 2004 May;190(5):1440-4. [PubMed] [Crossref]

3. Whiteman MK, Kuklina E, Hillis SD, Jamieson DJ, Meikle SF, Posner $\mathrm{SF}$, et al. Incidence and determinants of peripartum hysterectomy. Obstet Gynecol. 2006 Dec;108(6):1486-92. [PubMed] [Crossref]

4. Flood KM, Said S, Geary M, Robson M, Fitzpatrick C, Malone FD.
Changing trends in peripartum hysterectomy over the last 4 decades. Am J Obstet Gynecol. 2009 Jun;200(6): 632.e1-6. [PubMed] [Crossref]

5. Yucel O, Ozdemir I, Yucel N, Somunkiran A. Emergency peripartum hysterectomy: a 9-year review. Arch Gynecol Obstet. 2006 May;274(2):847. [PubMed] [Crossref]

6. Deneux-Tharaux C, Bonnet MP, Tort J. Epidemiology of post-partum haemorrhage. J Gynecol Obstet Biol Reprod (Paris). 2014 Dec;43(10):93650. [PubMed] [Crossref]

7. Sentilhes L, Vayssière C, Deneux -Tharaux C, Guy Aya A, Bayoumeu F, Bonnet MP, et al. Postpartum hemorrhage: guidelines for clinical practice from the French College of
Gynaecologists and Obstetricians (CNGOF): in collaboration with the French Society of Anesthesiology and Intensive Care (SFAR). Eur J Obstet Gynecol Reprod Biol. 2016 Mar;198: 12-21. [PubMed] [Crossref]

8. Said Ali A, Faraag E, Mohammed M, Elmarghany Z, Helaly M, Gadallah $\mathrm{A}$, et al. The safety and effectiveness of Bakri balloon in the management of postpartum hemorrhage: a systematic review. J Matern Fetal Neonatal Med. 2019 Apr 24:1-8. [PubMed] [Crossref]

9. Matsubara S, Takahashi $\mathrm{H}$. Bakri balloon for placenta accreta spectrum disorder: an alternative to caesarean hysterectomy? J Obstet Gynaecol. 2018 Nov;38(8):1186. [PubMed] [Crossref]

Please cite this article as: Totev T, Staneva D, Oslekov T, Stamenov G. Peripartum Hysterectomies - Leading Risk Factors and Causes. J of IMAB. 2020 Oct-Dec;26(4):3387-3389. DOI: https://doi.org/10.5272/jimab.2020264.3387

Received: 01/11/2019; Published online: 21/10/2020

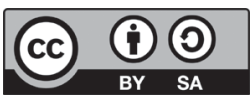

Address for correspondence:

Tihomir Totev MD, Ph D

Department of Obstetrics and Gynaecology, "Nadezhda" Women's Health Hospital - Sofia

3, Blaga vest str., Sofia, Bulgaria.

E-mail: t.totev@mail.bg, 